\title{
A Function Variant at miR-501 Alters Susceptibility to Hepatocellular Carcinoma in a Chinese Han Population
}

\author{
Yang Liu ${ }^{\mathrm{a}} \quad$ Yi Chai ${ }^{\mathrm{b}} \quad$ Jian Zhang ${ }^{\mathrm{a}}$ Junwei Tang ${ }^{\mathrm{b}}$ \\ ${ }^{a}$ Center for Translational Medicine, Guangxi Medical University, Pharmacology \& Biomedical Sciences \\ Building, Nanning, 'Liver Transplantation Center of the First Affiliated Hospital, Nanjing Medical \\ University, Nanjing, P.R. China
}

\section{Key Words}

miR-501 • Polymorphism • Proliferation • HCC • CYLD

\begin{abstract}
Backgroud/Aims: Previous studies have shown that miR-501 is involved in the development of hepatocellular carcinoma (HCC) by promoting cell proliferation through CYLD. From the published MirSNP database that enrolls all single nucleotide polymorphisms(SNPs) of microRNA (miRNA), we found an interesting SNP (rs112489955, G>A) located in the mature region of miR-501. Methods: We performed a case-control study focusing on the predicted SNP located in miRNA-501 to investigate the further relationship of the SNPs with miRNAs among HCC patients. Genotyping, real time PCR assay, cell transfection and the dual luciferase reporter assay were used in our study. Results: Bioinformatic analysis indicated that this SNP would inhibit the binding of miR-501 to CYLD. In a case-control study, subjects with the variant genotypes (AG, GG) showed a significantly increased risk of HCC relative to AA carriers. $A$ significant association of miR-501 variant genotypes with enhanced tumor growth was also observed. Further functional analyses indicated that patients with the AA genotype might attenuate the level of CYLD compared to that regulated by miR-501 with the GG genotype. A dual luciferase reporter assay also confirmed that miR-501 with the A allele had reduced binding to CYLD. We further confirmed a suppression of cell proliferation and promotion of apoptosis in SMMC-7721 and Hep3B cell lines treated with the AA genotype. Conclusions: We identified a novel SNP located in miR-501 acting as an important factor of the HCC susceptibility by modulating miR-501 and CYLD levels.

(C) 2016 The Author(s)

Published by S. Karger AG, Basel

\section{Introduction}

Hepatocellular carcinoma (HCC) accounts for 70\%-90\% of primary liver cancer, which has emerged as the fifth most common cancer and the second leading cause of cancer-

Jian Zhang, M.D., Ph.D.

and Junwei Tang, M.D., Ph.D.

KARGER

Center for Translational Medicine, Guangxi Medical University, No.22 Shuangyong Road, 1416 Pharmacology \& Biomedical Sciences Building, Nanning, Guangxi Province, 530021 (P.R. China) and Liver Transplantation Center of the First Affiliated Hospital , Nanjing Medical University, Nanjing, Jiangsu Province, (P.R. China)

E-Mail jzhangqi@gmail.com / pepsitjw@njmu.edu.com
\end{abstract}


Liu et al.: Functional SNP in miR-501

related deaths worldwide $[1,2]$.It is characterized by delayed diagnosis and poor prognosis $[3,4]$. With the development of high-throughput sequencing, it has been identified that the pathogenesis of HCC is highly associated with genetic factors, environmental factors, hepatitis B virus infection, as well as abnormal activation of signaling pathways [5-7]. Various single nucleotide polymorphisms (SNPs), as well as mutations, in protein-coding genes are involved in the development of HCC $[8,9]$. However, the SNPs or mutations located in noncoding RNA in HCC have not been investigated thoroughly.

Non-coding RNA, mainly including microRNA (miRNA) and long non-coding RNA, has been reported to play an important role in HCC by interacting with protein-coding genes, resulting in abnormal cell proliferation, invasion, differentiation, cell cycle changes or apoptosis [10-13]. Among these, miRNA was found to regulate negatively post-transcriptional gene expression by cleaving target mRNA or by inhibiting their translation [14-16]. For example, miR-145 acts as a tumor suppressor and its downregulation in tumor tissues may contribute to the progression and metastasis of HCC through a mechanism involving ROCK1, suggesting that miR-145 is a potential new diagnostic and therapeutic target for the treatment of HCC [17]. In addition, increasing evidence indicates that SNPs or mutations could make a significant contribution during the regulation of miRNA. MiR-27a, a genetic variant could contribute to gastric cancer susceptibility by affecting miR-27a and target gene expression,whereas miR-608 rs4919510 is associated with the prognosis of HCC $[18,19]$.

In this study, as a continuation of published research that identified that miR-501 regulates ubiquitin carboxyl-terminal hydrolase(CYLD) expression and promotes cell proliferation in human HCC, we focused on the SNP (rs112489955, G>A) located in the mature region of miR-501, based on the public database miRNA SNP (http://www.bioguo. org/miRNASNP/) that includes all the SNPs located in miRNAs [20, 21]. We further performed a case-control study to investigate whether this SNP in miR-501 is associated with the development of HCC or causes an abnormal regulation of CYLD.

\section{Materials and Methods}

\section{Patient samples}

Six-hundred and ninety-five patients with HCC and 605 healthy controls were enrolled in this study. Blood samples from both HCC patients and healthy controls were obtained from the First Affiliated Hospital of Nanjing Medical University (Nanjing, China). Informed consent for blood analysis was obtained prior to surgery. Experiments were undertaken with the understanding and written consent of each subject. Peripheral blood was collected before surgery. HCC cases were confirmed by histopathological analysis. The health of control individuals was confirmed by the absence of any malignant tumors, hereditary disease or autoimmune disease.This study was approved by the Institutional Review Board of Nanjing Medical University. All research was performed in compliance with government policies and the Helsinki Declaration.

\section{Genotyping}

Genomic DNA was isolated from the blood samples according to standard phenol and chloroform extraction procedures. The Taqman probe was used to detect the distribution of the genotype in all cases. The probe targeting the SNP (rs112489955) was purchased from Applied Biosystems (Life Technologies, CA, USA; Catalog \# 4351379). The polymerase chain reaction (PCR) assay was performed using an ABI 7900HT Real Time PCR instrument, as described by the manufacturer's instructions.

\section{Cell culture}

Human HCC cell lines, HepG2, SMMC-7721, MHCC-97H, SNU423, Huh7 and Hep3B, were obtained from the American Type Culture Collection (ATCC, Manassas, VA, USA). They were maintained in an atmosphere of $5 \% \mathrm{CO}_{2}$ in Dulbecco's modified eagle's medium (Thermo, Beijing,China) supplemented with $10 \%$ fetal bovine serum (Thermo,Beijing,China). Cell line authentication was performed by STR profiling before the initiation of the project.

\section{KARGER}


Quantitative real time polymerase chain reaction ( $q R T-P C R$ )

QRT-PCR was performed to determine the expression levels of miRNA-501 and CYLD of all related genes. Total RNA was obtained from tissues using TRIzol reagent, as described by the manufacturer (Invitrogen Life Technologies, CA, USA). The Taqman probe targeting miR-501 was obtained from ABI (Catalog \# A25576). U6 snRNA was used as an internal control. The primers for detecting the expression of CYLD were 5'-TCAGGCTTATGGAGCCAAGAA-3'and 5'-ACTTCCCTTCGGTACTTTAAGGA-3'.QRT-PCR was performed using an ABI Prism 7900HT instrument (Applied Biosystems) according to the directions provided with the reagents [22].

Luciferase reporter gene assay

The 3'-UTR sequence of CYLD predicted to interact with miR-501 (either with the GG genotype or with the AA genotype) or a mutated sequence with the predicted target sites were inserted into the pGL4 promoter vector. For reporter assay, cells were plated onto 24-well plates. A Renilla luciferase vector pRLSV40 (5 ng) was also co-transfected to normalize the differences in transfection efficiency.

Cell proliferation assays and cell apoptosis detection

The proliferative ability of HCC cell lines was detected by the EDU cell proliferation assay (Millipore, MA, USA). In brief, cells transfected with miR-501 mimics with different genotypes or controls were seeded at a density of $1 \times 10^{4}$ cells/well in flat-bottom 96-well plates and cultured for $48 \mathrm{~h}$. The absorbance values measured at $450 \mathrm{~nm}$ represent the rate of DNA synthesis following the EDU stain, and correspond to the number of proliferating cells.

For the apoptosis analysis, cells were washed in PBS, and then processed with Annexin V-FITC-PI Apoptosis Detection Kit (BD Biopharmingen, NJ, USA) for $15 \mathrm{~min}$ in the dark. All experiments were analyzed by BD Biasciences FACS Calibur Flow Cytometry (BD Biasciences, NJ, USA). The tests were repeated for three times with triplicate per experiment as described [13].

\section{Statistical methods}

All experiments were repeated independently at least three times. Data are expressed as the mean \pm SD. Differences between two independent groups were tested with Student's t-test. All statistical analyses were performed with Stata10.0 software, and are presented with GraphPad prism software. The results were considered to be statistically significant at $P<0.05$.

\section{Results}

SNP (rs112489955) is associated with the risk of HCC

We first calculated whether the SNP (rs112489955) located in the mature region of miR-501 would cause an abnormal hairpin structure. As presented in Fig. 1A, bioinformatic analysis revealed that the miR-501 with the AA genotype would develop another stem-loop in the hairpin structure. Further analysis predicted that miR-501 with the GG genotype could directly bind to the 3' UTR region of CYLD with the minimum free energy of $-25 \mathrm{kcal} / \mathrm{mol}$,

Fig. 1. Bioinformatic analysis of SNP located in miR501. A: The hairpin structure prediction in wild type miR-501 (left panel) and miR-501 with the SNP genotype (right panel). B: Prediction of the binding site of wild type miR-501 to the 3'UTR region of CYLD. The minimum free energy ( $\mathrm{mfe}$ ) was calculated by the Bibiserve database.

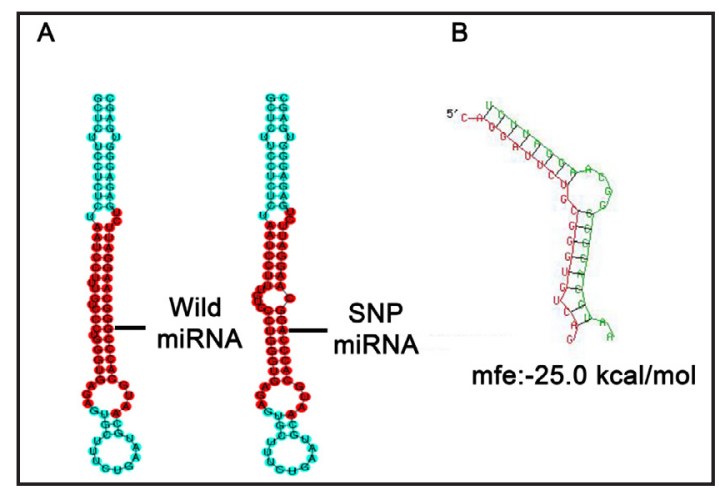


Table 1. Clinical characteristics of rs112489955 in HCC patients and cancer-free controls. *Two-sided chi-square test for ananlyzing the clinical characteristics of HCC patients and cancer-free controls

\begin{tabular}{|c|c|c|c|c|c|}
\hline \multirow{2}{*}{ Variables } & \multicolumn{2}{|c|}{ Cases $(n=695)$} & \multicolumn{2}{|c|}{ Controls $(n=605)$} & \multirow{2}{*}{$P^{*}$} \\
\hline & $N$ & $\%$ & $N$ & $\%$ & \\
\hline \multicolumn{6}{|l|}{ Age (years) } \\
\hline$\leq 60$ & 350 & 50.4 & 331 & 54.7 & 0.117 \\
\hline$>60$ & 345 & 49.6 & 274 & 45.3 & \\
\hline \multicolumn{6}{|l|}{ Gender } \\
\hline Male & 481 & 69.2 & 422 & 69.8 & 0.832 \\
\hline Female & 214 & 30.8 & 183 & 30.2 & \\
\hline \multicolumn{6}{|c|}{ Virus infection } \\
\hline $\mathrm{HBV} / \mathrm{HCV}$ & 578 & 83.2 & 22 & 3.6 & $<0.0001$ \\
\hline Negative & 117 & 16.8 & 583 & 96.4 & \\
\hline \multicolumn{6}{|c|}{ Alcohol exposure } \\
\hline Positive & 304 & 43.7 & 288 & 47.6 & 0.163 \\
\hline Negative & 391 & 56.3 & 317 & 52.4 & \\
\hline \multicolumn{6}{|c|}{ Smoking exposure } \\
\hline Positive & 298 & 42.9 & 277 & 45.8 & 0.292 \\
\hline Negetive & 397 & 57.2 & 328 & 54.2 & \\
\hline \multicolumn{6}{|c|}{ Hypertension } \\
\hline Positive & 319 & 45.9 & 291 & 48.1 & 0.428 \\
\hline Negetive & 376 & 54.1 & 314 & 51.9 & \\
\hline \multicolumn{6}{|c|}{ Diabetes mellitus } \\
\hline Positive & 202 & 29.1 & 175 & 28.9 & 0.956 \\
\hline Negetive & 493 & 70.9 & 430 & 71.1 & \\
\hline
\end{tabular}

Table 2. The genotype of the ploymorphisms rs112489955 in HCC patients and cancer-free controls. ${ }^{\text {aThe ORs, }}$ 95\% CIs and $P$ value were calculated after adjusting for age, gender

\begin{tabular}{|c|c|c|c|c|c|c|}
\hline \multirow{2}{*}{ Genotype } & \multicolumn{2}{|c|}{ Cases $(n=695)$} & \multicolumn{2}{|c|}{ Controls $(n=605)$} & \multirow{2}{*}{$\begin{array}{c}\text { OR } \\
(95 \% \mathrm{CI})^{\mathrm{a}}\end{array}$} & \multirow{2}{*}{$P$ Value ${ }^{2}$} \\
\hline & $N$ & $\%$ & $N$ & $\%$ & & \\
\hline GG & 422 & 60.7 & 322 & 53.2 & 1.00 & 0.007 \\
\hline GA & 144 & 20.7 & 151 & 25.0 & $0.77(1.12-1.19)$ & \\
\hline $\mathrm{AA}$ & 129 & 18.6 & 132 & 21.8 & $0.62(1.33-1.58)$ & \\
\hline A carrier & 273 & 39.3 & 283 & 46.8 & $0.65(1.25-1.35)$ & $<0.001$ \\
\hline
\end{tabular}

Table 3. The stratified analysis of association between rs112489955 and HCC risk. *Two-sided chi-square test for either genotype distributions or allele frequencies between cases and controls

indicating that the SNP located in miR-501 might be associated with the binding between miR-501 and CYLD (Fig. 1B).

Based on the aforementioned prediction results, we next conducted the genotype assay to detect the distribution of SNP (rs112489955) in a case-control study. All the individuals enrolled in the case group and control groups were age- and gender-matched (Table 1). The exposure to alcohol and smoking was calculated to

\begin{tabular}{|c|c|c|c|c|c|}
\hline \multirow{2}{*}{ Feather } & \multicolumn{3}{|c|}{ Genotype } & \multirow{2}{*}{$\begin{array}{l}\text { GA vs GG } \\
P \text { Value* }\end{array}$} & \multirow{2}{*}{$\begin{array}{l}\text { AA vs GG } \\
P \text { Value* }\end{array}$} \\
\hline & GG & GA & AA & & \\
\hline \multicolumn{6}{|c|}{ Differentiation grade } \\
\hline Well & 201 & 71 & 63 & 0.923 & 0.616 \\
\hline Moderate & 112 & 36 & 29 & & \\
\hline Poorly & 109 & 37 & 37 & & \\
\hline \multicolumn{6}{|c|}{ Tumor Number } \\
\hline Solitary & 122 & 40 & 31 & 0.795 & 0.279 \\
\hline Multiple & 300 & 104 & 98 & & \\
\hline \multicolumn{6}{|c|}{ Tumor Size(cm) } \\
\hline$\leq 5 \mathrm{~cm}$ & 188 & 78 & 75 & 0.046 & 0.007 \\
\hline$>5 \mathrm{~cm}$ & 234 & 66 & 54 & & \\
\hline \multicolumn{6}{|c|}{ Tumor Capsular } \\
\hline Incomplete & 139 & 51 & 37 & 0.587 & 0.364 \\
\hline Complete & 283 & 93 & 92 & & \\
\hline \multicolumn{6}{|l|}{ Metastasis } \\
\hline Yes & 168 & 62 & 41 & 0.494 & 0.100 \\
\hline No & 254 & 82 & 88 & & \\
\hline \multicolumn{6}{|l|}{ AFP } \\
\hline High & 177 & 68 & 45 & 0.270 & 0.153 \\
\hline Low & 245 & 76 & 84 & & \\
\hline
\end{tabular}


A

C

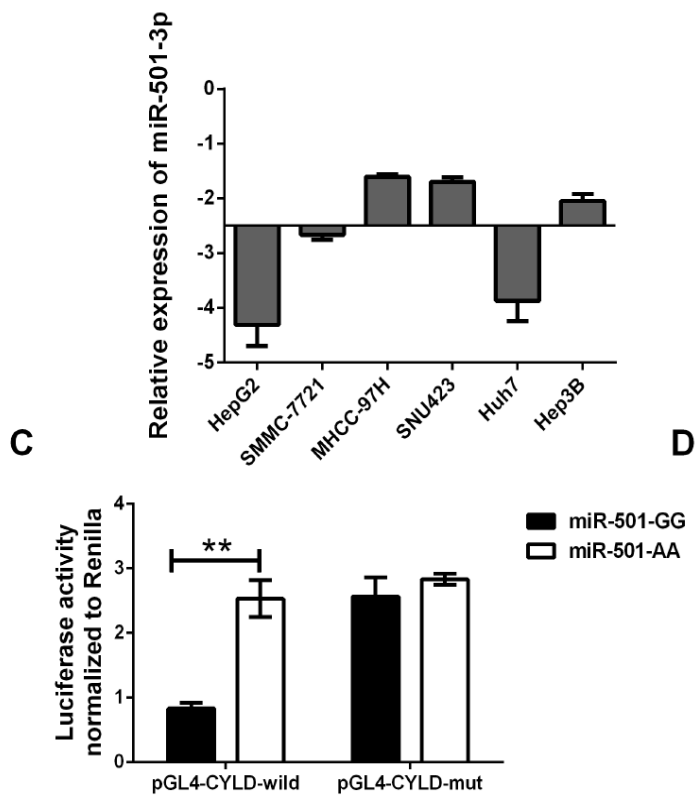

B

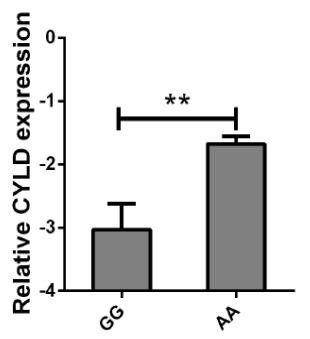

D

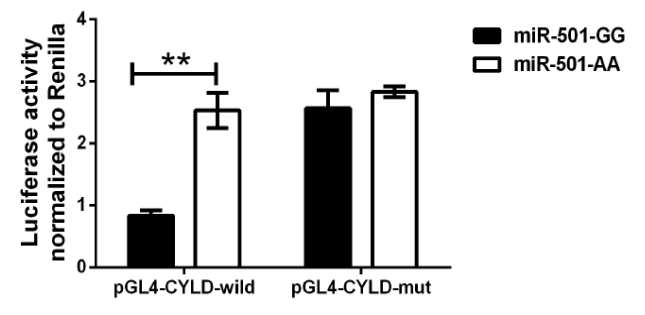

Fig. 2. SNPs located in miR-501 can increase the level of CYLD in vitro. A: The expression of wild type miR501 in different HCC cell lines.The data were converted to the log scale. B: The expression of CYLD was detected in SMMC-7721 cells treated with miR-501 with wild type (GG) and SNP type (AA). Data are shown on a log scale. C: The firefly and Renilla luciferase activities in SMMC-7721 cells treated with miR-501 (both wild type and SNP type). Firefly luciferase signals were normalized with Renilla luciferase signals. D: The firefly and Renilla luciferase activities in Hep3B cells treated with miR-501 (both wild type and SNP type). Firefly luciferase signals were normalized with Renilla luciferase signals. Data are presented as the mean \pm SD. ** indicates $P<0.01$.

be at the same level in the two groups. There was also no difference between the case and control subjects in terms of hypertension or diabetes mellitus, indicating that the match of controls and cases was adequate. Further genotype detection showed that the distribution of the GG genotype in cases (69.7\%) was higher than in control groups(53.2\%), whereas the A alleles in cases $(39.3 \%)$ was lower than that in the control group(46.8\%). Taking the GG genotype as a reference, the difference in rs112489955 genotype distributions between the cases and controls was statistically significant $(P=0.007)$, and the distribution of the A allele in the two groups was also significantly different $(P<0.001)$. The genotype distribution in the cases and controls was in agreement with the Hardy-Weinberg equilibrium (Table 2).

SNP (rs112489955) is associated with tumor growth

According to a previous report, miR-501 is associated with the proliferation of HCC cell lines by regulating CYLD. We therefore analyzed the association of different genotypes of miR-501 with different clinical characteristics of HCC patients. As presented in Table 3, the tumor differentiation grade, tumor number, tumor size, tumor capsular and metastasis information was collected. We found that patients with GG genotype presented with a larger tumor size compared to patients with GA or AA genotypes. However, no difference was obtained in other subgroups, indicating that the SNP rs112489955 might be associated with cell proliferation through a CYLD-dependent pathway.

The basal expression of miR-501 in human HCC cell lines, including HepG2, SMMC-7721, MHCC-97H, SNU423, Huh7 and Hep3B was measured. For the next step, we selected SMMC7721 and Hep3B cell lines (Fig. 2A). We first detect the expression of CYLD mRNA in the two cells transfected with miR-501 with different genotypes. We found that the expression of CYLD in cells treated with wild type miR-501 was decreased compared with the SNP 


\section{A $\quad$ SMMC-7721}
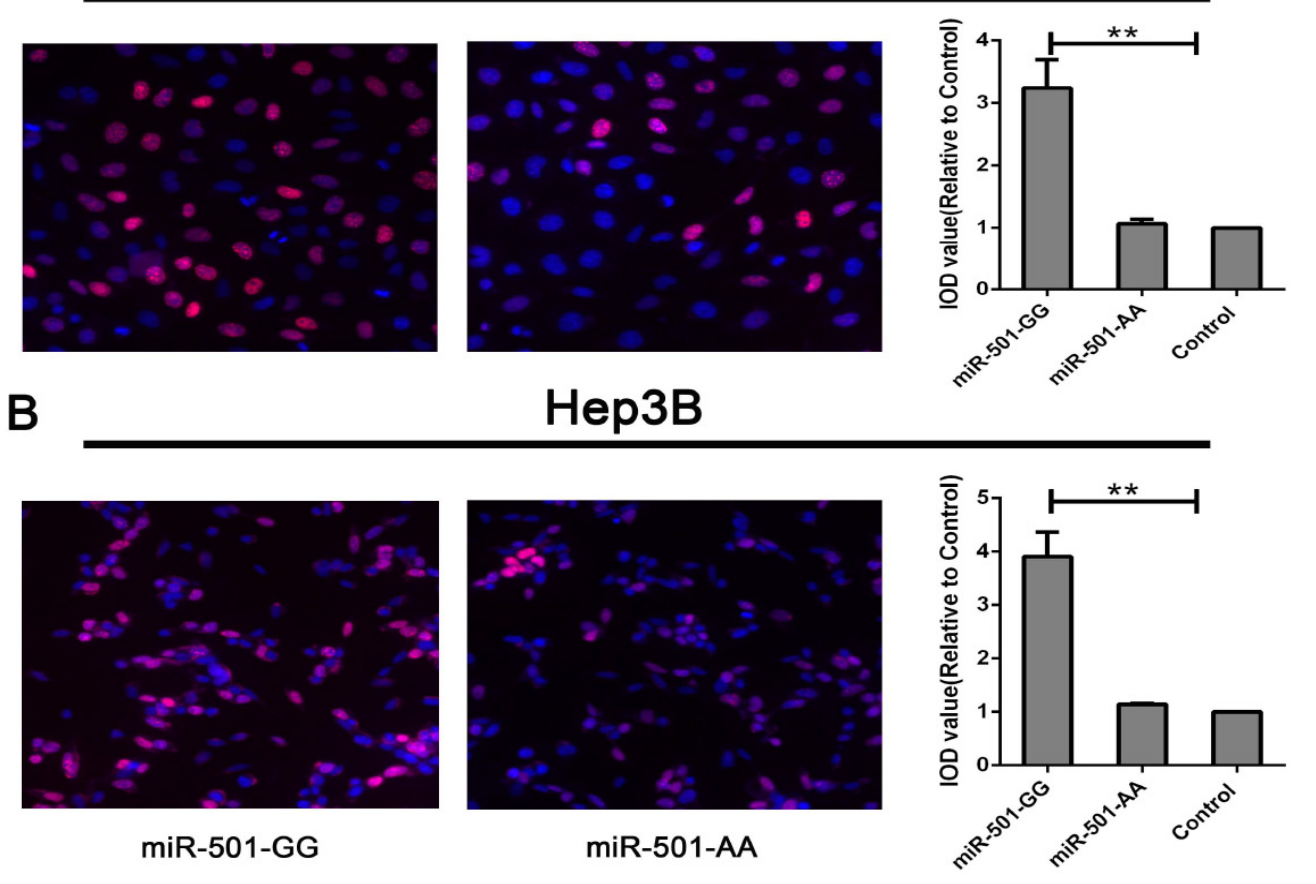

Fig. 3. SNPs located in miR-501 can suppress cell proliferation in vitro. Proliferating cells were stained with EDU, displayed as red fluorescence. 4',6-diamidino-2-phenylindole(DAPI) was used as a nuclear stain. HCC cell lines were treated with different types of miR-501. The data were normalized with the control group and presented as the mean \pm SD. ${ }^{* *}$ indicates $P<0.01$. Panel A ,SMMC-7721 cells; panel B, Hep3B cells.

genotypes (Fig. 2B). Experiments involving the detection of dual luciferase activity also confirmed that the existence of the A allele could cause the inhibition of miR-501 binding to CYLD (Fig. 2C, D).

The proliferation and apoptosis of SMMC-7721 and Hep3B cells was monitored via the EDU assay and flow cytometry, respectively. Interestingly, cell proliferation was promoted by treatment with miR-501 wild type mimics, consistent with a previous report. However, the activated proliferation could be attenuated by transfecting cells with miR-501 SNP genotypes (Fig. 3A, B) while the cell apoptosis could be promoted by cells treated with miR-501 with AA genotype(Fig. 4A, B).

\section{Discussion}

In the present study, we found that the common polymorphisms within miR-501 (rs112489955) are associated with a significantly decreased risk of HCC. Preliminary functional assays revealed that the miR-polymorphism conferred an increased level of CYLD as a result of the diminished binding to CYLD. We also found that the SNP located in the mature region of miR-501 might cause suppressed cell proliferation as compared with the wild type.

CYLD, a deubiquitination enzyme, functions as a tumor suppressor in different types of cancer, such as melanoma, and basal cell, colon and HCCs [23-26]. CYLD can translocate to the perinuclear region and bind the IкB family member Bcl-3, and removes K63-linked poly ubiquitin chains upon stimulation. This prevents the nuclear translocation of Bcl-3-p50 and Bcl-3-p52 complexes [27, 28]. In addition, downregulation of CYLD induces tumor cell

\section{KARGER}




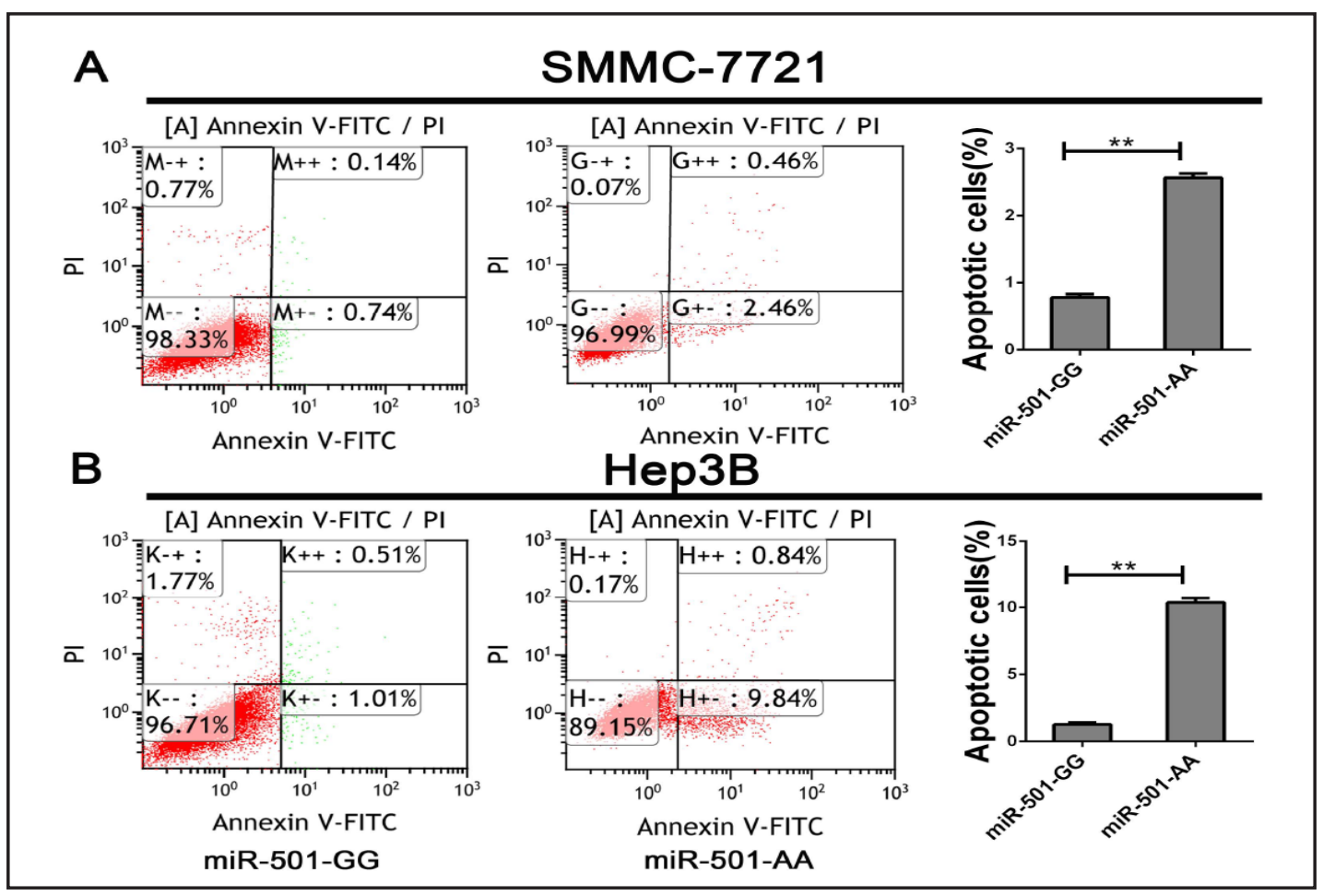

Fig. 4. SNPs located in miR-501 can promote cell apoptosis in vitro. Apoptotic cells were detected by flow cytometry. HCC cell lines were treated with different types of miR-501. Data was presented as the mean \pm SD. ** indicates $P<0.01$. Panel A ,SMMC-7721 cells; panel B, Hep3B cells.

proliferation, consequently contributing to the aggressive growth of HCC [29, 30]. In this study, we found an increased level of CYLD and decreased cell proliferation in cells treated with SNP type miR-501. We also found that and the tumor size in patients with the AA genotype is smaller compared to those with the other genotypes.The expression of CYLD is suppressed in cells treated with wild type miR-501, as detected by the dual luciferase activity, and is accompanied by an increase in cell proliferation.

Recently, a class of novel functional polymorphisms in miRNAs and their binding sites has been described, and has been shown to be highly associated with the susceptibility of multiple human malignant tumors.Until now, the SNP (rs11614913) in miR-196a and the variant genotypes(rs3746444) in miR-499 were associated with a significantly increased risk of breast cancer in Chinese women [31, 32]. Moreover, theses studies suggested that a variant homozygote of rs11614913 in miR-196a is associated with poor survival in patients with non-small cell lung cancer [33]. Consistently, Zhou et al. indicated that a SNP rs41274221 located in the mature region of miR-25 is a subgroup which may protect patients from further growth and metastasis of gastric cancer, and might serve as a novel biomarker for gastric cancer.They also showed that SNP rs9589207 in miR-92a is highly associated with a decreased risk of gastric cancer in the Chinese Han population [34, 35].

This is the first report on the stimulatory effect of the functional polymorphism of miR501 on CYLD which could suppress cell proliferation and promote cell apoptosis in vitro. Nevertheless, this study is limited, because it is a hospital-based case-control study that might have caused selection bias.

\section{Funding}

This study was funded by Innovation project of Jiangsu Province (KYLX_0935 to T.J.) 


\section{Acknowledgments}

Informed consent was obtained from all individual participants included in the study.

\section{Disclosure Statement}

The authors declare that they have no financial conflict of interest.

\section{References}

1 Trepo C, Chan HL, Lok A: Hepatitis B virus infection. Lancet 2014;384:2053-2063.

2 Jiang DK, Sun J, Cao G, Liu Y, Lin D, Gao YZ, Ren WH, Long XD, Zhang H, Ma XP, Wang Z, Jiang W, Chen TY, Gao Y, Sun LD, Long JR, Huang HX, Wang D, Yu H, Zhang P, Tang LS, Peng B, Cai H, Liu TT, Zhou P, Liu F, Lin X, Tao S, Wan B, Sai-Yin HX, Qin LX, Yin J, Liu L, Wu C, Pei Y, Zhou YF, Zhai Y, Lu PX, Tan A, Zuo XB, Fan J, Chang J, Gu X, Wang NJ, Li Y, Liu YK, Zhai K, Zhang H, Hu Z, Liu J, Yi Q, Xiang Y, Shi R, Ding Q, Zheng W, Shu XO, Mo Z, Shugart YY, Zhang XJ, Zhou G, Shen H, Zheng SL, Xu J, Yu L: Genetic variants in STAT4 and HLA-DQ genes confer risk of hepatitis B virus-related hepatocellular carcinoma. Nat Genet 2013;45:72-75.

3 Yong KJ, Gao C, Lim JS, Yan B, Yang H, Dimitrov T, Kawasaki A, Ong CW, Wong KF, Lee S, Ravikumar S, Srivastava S, Tian X, Poon RT, Fan ST, Luk JM, Dan YY, Salto-Tellez M, Chai L, Tenen DG: Oncofetal gene SALL4 in aggressive hepatocellular carcinoma. N Engl J Med 2013;368:2266-2276.

4 Zucman-Rossi J, Villanueva A, Nault JC, Llovet JM: Genetic Landscape and Biomarkers of Hepatocellular Carcinoma. Gastroenterology 2015;149:1226-1239 e1224.

5 Arzumanyan A, Reis HM, Feitelson MA: Pathogenic mechanisms in HBV- and HCV-associated hepatocellular carcinoma. Nat Rev Cancer 2013;13:123-135.

6 Farazi PA, DePinho RA: Hepatocellular carcinoma pathogenesis: from genes to environment. Nat Rev Cancer 2006;6:674-687.

7 Levi AD, Wallace MC, Bernstein M, Walters BC: Venous thromboembolism after brain tumor surgery: a retrospective review. Neurosurgery 1991;28:859-863.

8 Miki D, Ochi H, Hayes CN, Abe H, Yoshima T, Aikata H, Ikeda K, Kumada H, Toyota J, Morizono T, Tsunoda T, Kubo M, Nakamura Y, Kamatani N, Chayama K: Variation in the DEPDC5 locus is associated with progression to hepatocellular carcinoma in chronic hepatitis C virus carriers. Nat Genet 2011;43:797-800.

9 GoDarts, Group UDPS, Wellcome Trust Case Control C, Zhou K, Bellenguez C, Spencer CC, Bennett AJ, Coleman RL, Tavendale R, Hawley SA, Donnelly LA, Schofield C, Groves CJ, Burch L, Carr F, Strange A, Freeman C, Blackwell JM, Bramon E, Brown MA, Casas JP, Corvin A, Craddock N, Deloukas P, Dronov S, Duncanson A, Edkins S, Gray E, Hunt S, Jankowski J, Langford C, Markus HS, Mathew CG, Plomin R, Rautanen A, Sawcer SJ, Samani NJ, Trembath R, Viswanathan AC, Wood NW, investigators M, Harries LW, Hattersley AT, Doney AS, Colhoun H, Morris AD, Sutherland C, Hardie DG, Peltonen L, McCarthy MI, Holman RR, Palmer CN, Donnelly P, Pearson ER: Common variants near ATM are associated with glycemic response to metformin in type 2 diabetes. Nat Genet 2011;43:117-120.

10 Ling H, Fabbri M, Calin GA: MicroRNAs and other non-coding RNAs as targets for anticancer drug development. Nat Rev Drug Discov 2013;12:847-865.

11 Hou J, Lin L, Zhou W, Wang Z, Ding G, Dong Q, Qin L, Wu X, Zheng Y, Yang Y, Tian W, Zhang Q, Wang C, Zhang Q, Zhuang SM, Zheng L, Liang A, Tao W, Cao X: Identification of miRNomes in human liver and hepatocellular carcinoma reveals miR-199a/b-3p as therapeutic target for hepatocellular carcinoma. Cancer Cell 2011;19:232-243.

12 Chang Y, Yan W, He X, Zhang L, Li C, Huang H, Nace G, Geller DA, Lin J, Tsung A: miR-375 inhibits autophagy and reduces viability of hepatocellular carcinoma cells under hypoxic conditions. Gastroenterology 2012;143:177-187 e178.

13 Tang J, Zhuo H, Zhang X, Jiang R, Ji J, Deng L, Qian X, Zhang F, Sun B: A novel biomarker Linc00974 interacting with KRT19 promotes proliferation and metastasis in hepatocellular carcinoma. Cell Death Dis 2014;5:e1549.

14 Tang W, Tang J, He J, Zhou Z, Qin Y, Qin J, Li B, Xu X, Geng Q, Jiang W, Wu W, Wang X, Xia Y: SLIT2/ROBO1miR-218-1-RET/PLAG1: a new disease pathway involved in Hirschsprung's disease. J Cell Mol Med 2015;19:1197-1207. 
15 Gao F, Sun X, Wang L, Tang S, Yan C: Downregulation of MicroRNA-145 Caused by Hepatitis B Virus X Protein Promotes Expression of CUL5 and Contributes to Pathogenesis of Hepatitis B Virus-Associated Hepatocellular Carcinoma. Cell Physiol Biochem 2015;37:1547-1559.

$16 \mathrm{Hu}$ X, Zhang F, Liu XR, Wu YT, Ni YM: Efficacy and potential microRNA mechanism for computed tomography-guided percutaneous radiofrequency ablation of primary lung cancer and lung metastasis from liver cancer. Cell Physiol Biochem 2014;33:1261-1271.

17 Zheng M, Sun X, Li Y, Zuo W: MicroRNA-145 inhibits growth and migration of breast cancer cells through targeting oncoprotein ROCK1. Tumour Biol 2015;10.1007/s13277-015-4722-2

18 Sun Q, Gu H, Zeng Y, Xia Y, Wang Y, Jing Y, Yang L, Wang B: Hsa-mir-27a genetic variant contributes to gastric cancer susceptibility through affecting miR-27a and target gene expression. Cancer Sci 2010;101:22412247.

19 Wang R, Zhang J, Ma Y, Chen L, Guo S, Zhang X, Ma Y, Wu L, Pei X, Liu S, Wang J, Hu H, Liu J: Association study of miR149 rs2292832 and miR608 rs4919510 and the risk of hepatocellular carcinoma in a largescale population. Mol Med Rep 2014;10:2736-2744.

20 Huang DH, Wang GY, Zhang JW, Li Y, Zeng XC, Jiang N: MiR-501-5p regulates CYLD expression and promotes cell proliferation in human hepatocellular carcinoma. Jpn J Clin Oncol 2015;45:738-744.

21 Gong J, Tong Y, Zhang HM, Wang K, Hu T, Shan G, Sun J, Guo AY: Genome-wide identification of SNPs in microRNA genes and the SNP effects on microRNA target binding and biogenesis. Hum Mutat 2012;33:254263.

22 Wang Y, Wu P, Lin R, Rong L, Xue Y, Fang Y: LncRNA NALT interaction with NOTCH1 promoted cell proliferation in pediatric T cell acute lymphoblastic leukemia. Sci Rep 2015;5:13749.

23 Ishikawa Y, Tsunoda K, Shibazaki M, Takahashi K, Akasaka T, Masuda T, Maesawa C: Downregulation of cylindromatosis gene, CYLD, confers a growth advantage on malignant melanoma cells while negatively regulating their migration activity. Int J Oncol 2012;41:53-60.

24 Shiver M, Hughes M, Naylor M, McLarney B, Stolle C, Shalin S, Gao L: A novel CYLD gene mutation and multiple basal cell carcinomas in a patient with Brooke-Spiegler syndrome. Clin Exp Dermatol 2016;41:98100.

25 Degagne E, Pandurangan A, Bandhuvula P, Kumar A, Eltanawy A, Zhang M, Yoshinaga Y, Nefedov M, de Jong PJ, Fong LG, Young SG, Bittman R, Ahmedi Y, Saba JD: Sphingosine-1-phosphate lyase downregulation promotes colon carcinogenesis through STAT3-activated microRNAs. J Clin Invest 2014;124:5368-5384.

26 Pannem RR, Dorn C, Ahlqvist K, Bosserhoff AK, Hellerbrand C, Massoumi R: CYLD controls c-MYC expression through the JNK-dependent signaling pathway in hepatocellular carcinoma. Carcinogenesis 2014;35:461-468.

27 Gringhuis SI, Kaptein TM, Wevers BA, Mesman AW, Geijtenbeek TB: Fucose-specific DC-SIGN signalling directs T helper cell type-2 responses via IKKepsilon- and CYLD-dependent Bcl3 activation. Nat Commun 2014;5:3898.

28 Ke H, Augustine CK, Gandham VD, Jin JY, Tyler DS, Akiyama SK, Hall RP, Zhang JY: CYLD inhibits melanoma growth and progression through suppression of the JNK/AP-1 and beta1-integrin signaling pathways. J Invest Dermatol 2013;133:221-229.

29 Gautheron J, Luedde T: A novel player in inflammation and cancer: the deubiquitinase CYLD controls HCC development. J Hepatol 2012;57:937-939.

30 Urbanik T, Kohler BC, Boger RJ, Worns MA, Heeger S, Otto G, Hovelmeyer N, Galle PR, Schuchmann M, Waisman A, Schulze-Bergkamen H: Down-regulation of CYLD as a trigger for NF-kappaB activation and a mechanism of apoptotic resistance in hepatocellular carcinoma cells. Int J Oncol 2011;38:121-131.

31 Zhao H, Xu J, Zhao D, Geng M, Ge H, Fu L, Zhu Z: Somatic Mutation of the SNP rs11614913 and Its Association with Increased MIR 196A2 Expression in Breast Cancer. DNA Cell Biol 2015;10.1089/ dna.2014.2785

32 Dai ZJ, Shao YP, Wang XJ, Xu D, Kang HF, Ren HT, Min WL, Lin S, Wang M, Song ZJ: Five common functional polymorphisms in microRNAs (rs2910164, rs2292832, rs11614913, rs3746444, rs895819) and the susceptibility to breast cancer: evidence from 8361 cancer cases and 8504 controls. Curr Pharm Des 2015;21:1455-1463.

33 Liu CJ, Tsai MM, Tu HF, Lui MT, Cheng HW, Lin SC: miR-196a overexpression and miR-196a2 gene polymorphism are prognostic predictors of oral carcinomas. Ann Surg Oncol 2013;20 Suppl 3:S406-414.

34 Zhou J, Zhou J, Wang W, Li W, Wu L, Li G, Shi J, Zhou S: The polymorphism in miR-25 attenuated the oncogenic function in gastric cancer. Tumour Biol 2015;10.1007/s13277-015-4376-0

35 Liu C, Zhang Y, Chen H, Jiang L, Xiao D: Function analysis of rs9589207 polymorphism in miR-92a in gastric cancer. Tumour Biol 2015;10.1007/s13277-015-4288-z. 